\title{
TEM STUDY OF DEFECTS IN LATERALLY OVERGROWN GaN LAYERS
}

Z. Liliental-Weber, M. Benamara, W. Swider, J. Washburn, J. Park,* P. A. Grudowski,* C. J. Eiting,* and R. D. Dupuis*

Materials Science Division, Lawrence Berkeley National Laboratory, Berkeley CA 94720, $62 / 203$

* Microelectronics Research Center, The University of Texas at Austin, Austin TX 78712-1100

\section{ABSTRACT}

Transmission electron microscopy was applied to study defects in laterally overgrown GaN layers, with initial growth on $\mathrm{Al}_{2} \mathrm{O}_{3}$ substrates followed by further growth over $\mathrm{SiO}_{2}$ masks. Dislocations found in the overgrown areas show changes in line direction. Most dislocations propagate along c-planes. In the overgrown material planar defects (faulted loops) are present on c-planes and their presence is most probably related to segregation of excess point defects and impurities present in this material. They appear to be initiated by the fast lateral growth. Some dislocations with screw orientation become helical resulting from climb motion.

Formation of voids and also a high dislocation density was observed at the boundaries where two overgrowing fronts meet. Tilt and twist components were observed for these boundaries that were different for different overgrown strips grown in the same crystallographic direction suggesting that the $\mathrm{GaN}$ subgrain orientations on the two sides of a $\mathrm{SiO}_{2}$ mask are responsible for the final tilt and twist value.

\section{INTRODUCTION}

Lack of good lattice match for epitaxial growth of $\mathrm{GaN}$ on $\mathrm{Al}_{2} \mathrm{O}_{3}$ or $\mathrm{SiC}$ results in high dislocation density. The lateral epitaxial overgrowth (LEO) technique is a promising method to reduce dislocation density in heteroepitaxial systems. It has recently been utilized in the deposition of GaN by metal organic chemical vapor deposition (MOCVD) [1-5]. The LEO approach consists of masking parts of the defective epilayer ( $\mathrm{GaN}$ grown on $\mathrm{Al}_{2} \mathrm{O}_{3}$ or $\mathrm{SiC}$ ) with thin strips of an amorphous layer so that the dislocations under the mask are prevented from propagating into the overgrown parts of the layer during subsequent growth. Several recent reports [1-7] for this type of growth show substantial reduction of threading dislocation density.

\section{EXPERIMENTAL AND DISCUSSION}

The III-N epitaxial films for this work were grown by low-pressure MOCVD in an EMCORE D125 reactor system at a pressure $\sim 100$ Torr and at temperatures in the range $1030 ; \mathrm{C}$ ${ }^{2} \mathrm{Tg}^{2} 1100_{i} \mathrm{C}$. Hydrogen was used as the main process gas and also as the carrier gas for the metal alkyl sources. Trimethylgallium (TMGa), and trimethylaluminium (TMAl) were used as Column III precursors. High-purity ammonia was used as the $\mathrm{N}$ source. Typical molar flow rates were $[\mathrm{TMGa}] \sim 2 \times 10^{-4} \mathrm{~mole} / \mathrm{min}$ and $[\mathrm{NH} 3] \sim 0.57 \mathrm{~mole} / \mathrm{min}$, resulting in V/III ratios $\sim 2,800$. First, (0001) GaN heteroepitaxial "substrates" were prepared by growing $\sim 2 \mu \mathrm{m}$ of doped or undoped $\mathrm{GaN}$ on (0001) sapphire at $\mathrm{Tg} \sim 1050 ; \mathrm{C}$. Silicon dioxide $\left(\mathrm{SiO}_{2}\right) 100 \mathrm{~nm}$ thick was then 
used as a mask material to produce selective-area growth. These masks were then patterned exposing parallel or concentric strips. Overgrown strips oriented along the $[1 \overline{1} 00]$ and $[11 \overline{2} 0]$ directions have been studied.

Transmission electron microscopy was applied to study the structure of GaN films grown on these patterned substrates. Cross-section and plan-view thin films were prepared. Two types of overgrown areas were studied, those where overgrown areas were separated from each other and cases where overgrown areas were allowed to meet .

Different shapes of the overgrown strips for the separated overgrowths were observed (Fig. 1). A majority of the strips grown along [1 $\overline{1} 00$ ] direction had rectangular or trapezoidal shapes with flat surfaces on (0001). The walls of the rectangular strips were along $(11 \overline{2} 0)$ planes, but in the trapezoidal strips the inclined walls were on (1 101$)$ planes. However, the strips grown along [11 $\overline{2} 0]$ direction were triangular, with inclined walls along $\{1 \overline{1} 01\}$ planes. Occasionally more complicated wall shapes were also observed. It appears that the shape or faceting is also influenced by impurity presence. Fig. 2 shows that the overgrowth started with a rectangular shape, but the shape changed presumably when impurities started to accumulate on the facet walls.

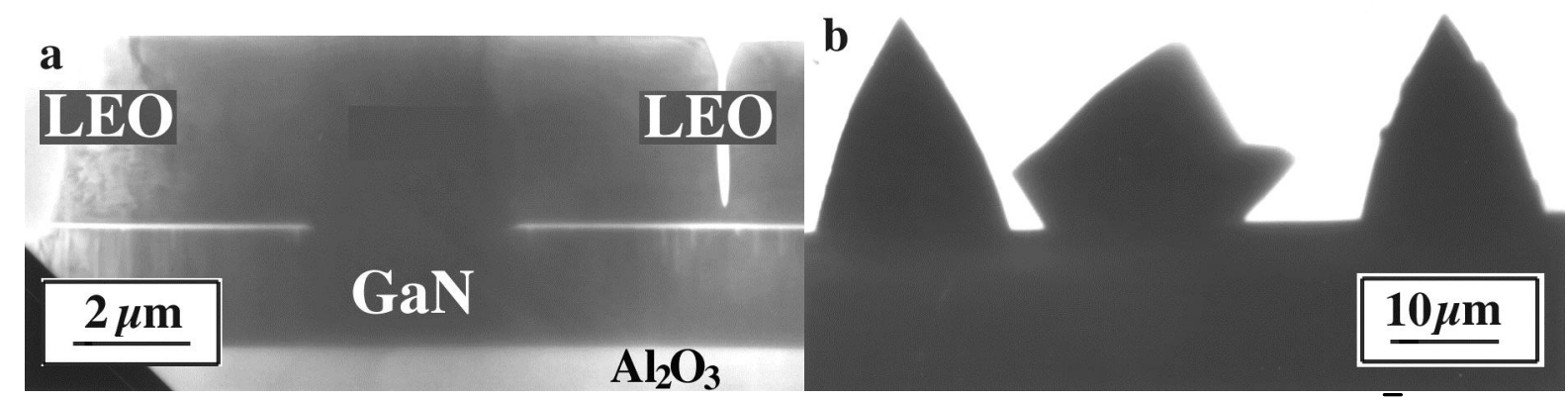

Fig. 1. Cross-section micrographs obtained for the GaN strips grown: (a) along [1 $\overline{1} 00]$ and (b) [11 20$]$ directions.

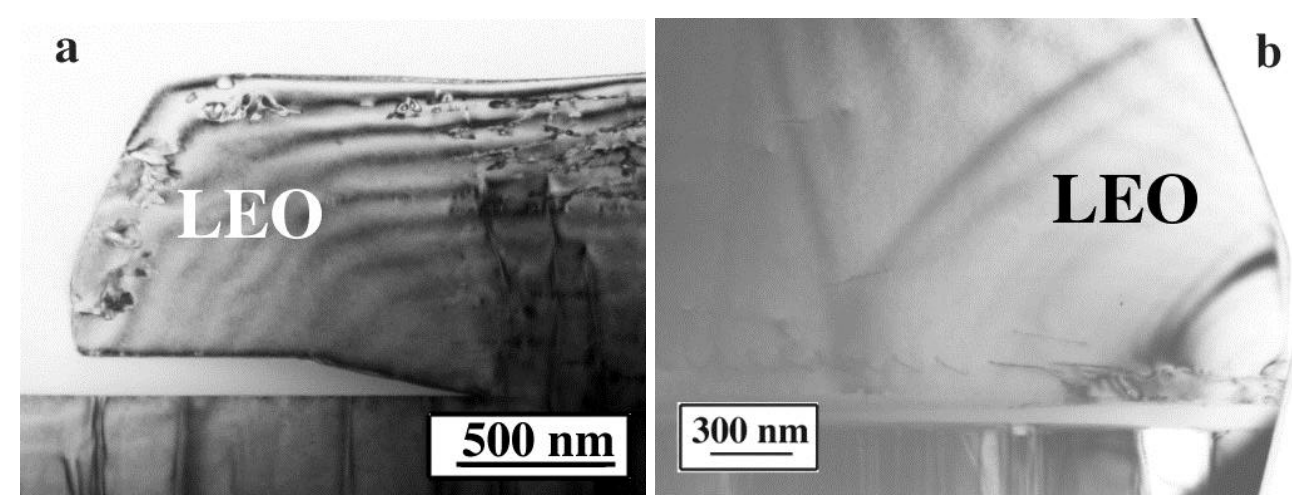

Fig. 2. (a) Cross-section TEM micrograph showing the shape of the overgrown strip near the $\mathrm{SiO}_{2}$ mask edge. Note change of shape from rectangular to the inclined on (1 101$)$; (b) Micrograph showing bending of dislocations close to the $\mathrm{SiO}_{2}$ mask.

Different types and different densities of defects were observed for the open areas between masks (homoepitaxial growth) and in the areas above the $\mathrm{SiO}_{2}$ masks (lateral overgrowth). In the homoepitaxial parts threading dislocations were present with the dislocation density in the range of $7 \times 10^{8} \mathrm{~cm}^{-2}$. However, in the overgrown areas defect densities and their type varied depending on the lateral growth rate, strip shape and depending on whether two strips 
came into contact with each other or if the strips remained separated. In the separated strips defect density was much lower.

Schematically the distribution of dislocations is shown in Fig. 3. In the free standing triangular strips all dislocations present in the homoepitaxial parts ("open mask") bend toward the side walls. At some particular hight of the triangle each threading dislocation will become close to a side wall. The image force will then cause dislocation bending toward the free surface in order to decrease the length of dislocation line. This phenomenon was previously observed in GaN for dislocations bending toward pinhole walls [8-9]. In this case only the triangular tip will be free of threading dislocations, as was also observed in the pyramids grown on SiC through circular openings [2].

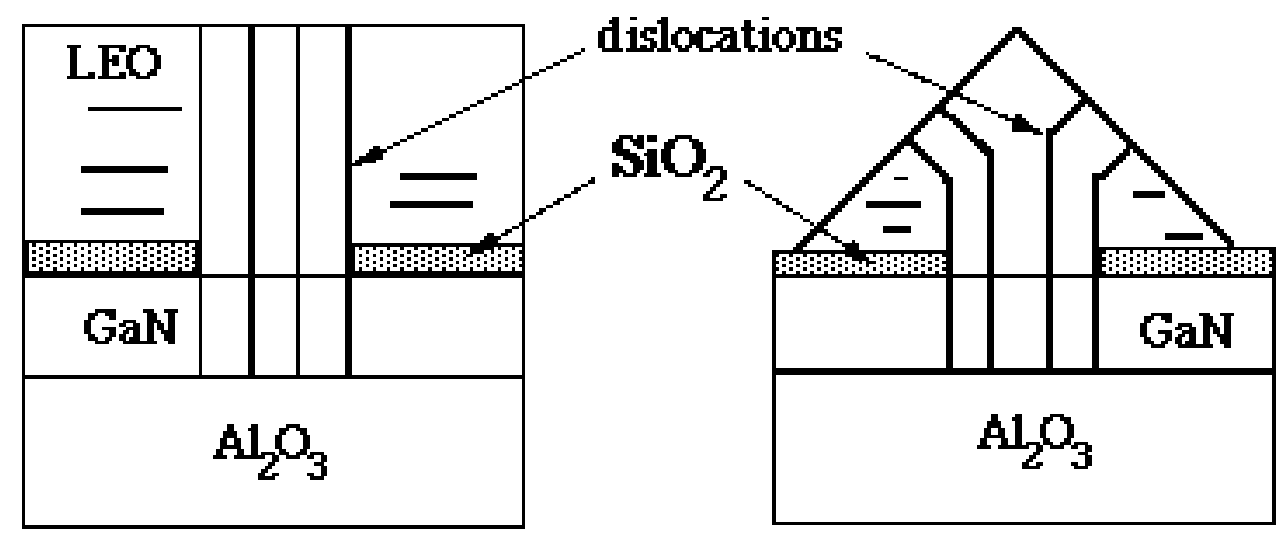

Fig. 3. Schematic showing bending of dislocations: (a) in the rectangular and (b) in the triangular shape strips.

In the case of the rectangular strips, depending on the lateral growth rate only a few of the dislocations located close to the $\mathrm{SiO}_{2}$ mask edge will be at a close enough distance from the strip wall, that the image force can cause their bending toward the free surface. If the lateral growth rate is fast enough then bent dislocations should be found only close to the $\mathrm{SiO}_{2}$ mask and further vertical growth over the mask should be threading dislocation free. This was observed experimentally (Fig. 2b). For areas above the $\mathrm{SiO}_{2}$ mask no vertical threading dislocations along the $\mathrm{c}$ axis were observed.

Plan-view micrographs show a very specific distribution of dislocations. In the homoepitaxial parts defect density remains practically unchanged compared to traditional growth of GaN on sapphire. They are often distributed as small angle grain boundaries. At the border where lateral growth starts, dislocations elongated along the strip were observed (Fig. 4a). Some of them bend toward the side walls of the strips. Dislocation density in the overgrown areas is much smaller, and even when they are present their line direction is almost parallel to the sample surface. They do not propagate to the top layers. However, much higher density of dislocations (about $10^{12} \mathrm{~cm}-2$ ) was observed where two strips meet (Fig. 4b). These dislocations will propagate to the layers grown on top. Different contrast on the two sides of such a border is observed showing the misorientation.

However, other typical defects are present in the overgrown areas. Planar defects such as faulted prismatic dislocation loops were observed. They are all formed on the c planes (Fig. 5a) and their density is in the range of $10^{9}-10^{10} \mathrm{~cm}^{-2}$. These defects are similar to the defects 
observed in bulk GaN platelets grown from a Ga melt under a high hydrostatic pressure of nitrogen [10].

Because of the high growth rate in the lateral direction a growth mistake due to accumulation of point defects or impurities can lead to the formation of stacking faults on the c planes and therefore, to the formation of prismatic dislocation loops on these planes.

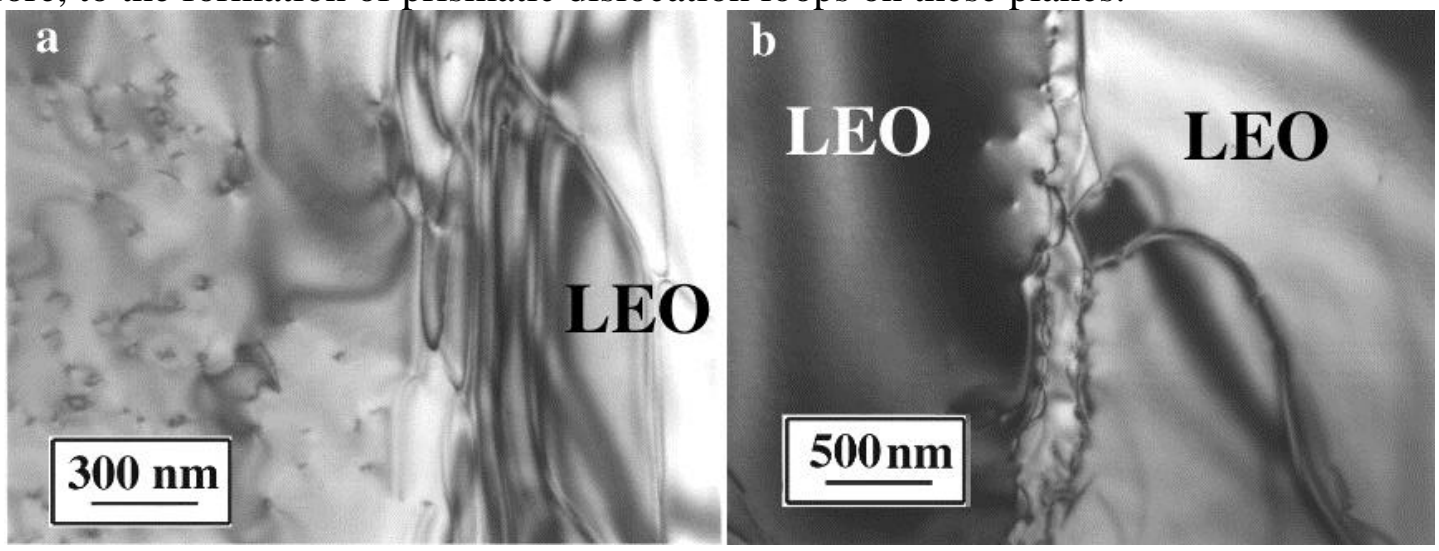

Fig. 4. Plan-view micrograph showing: (a) the interface between the homoepitaxial GaN with dislocations at grain boundaries and the area where the overgrowth starts with dislocation lines along the strip length; (b) meeting fronts of two strips showing high dislocation density.

This high growth rate in the lateral direction prevents formation of straight threading dislocations and the formation of pinholes and nanotubes. However, both these defects, pinholes and nanotubes were observed near the boundary where two overgrown fronts meet. At each such meeting front a large void was formed extending approximately about $10 \mathrm{~nm}$ above the oxide mask. In most cases such a void is like a pinhole with facets on (1 $\overline{101})$ planes (Fig. 6). It is believed that formation of these voids is related to impurity accumulation at the meeting fronts (similarly as for formation of pinholes [8,9]). Only when the local impurity level decreases (at a greater distance from the $\mathrm{SiO}_{2}$ mask) can such voids be overgrown.
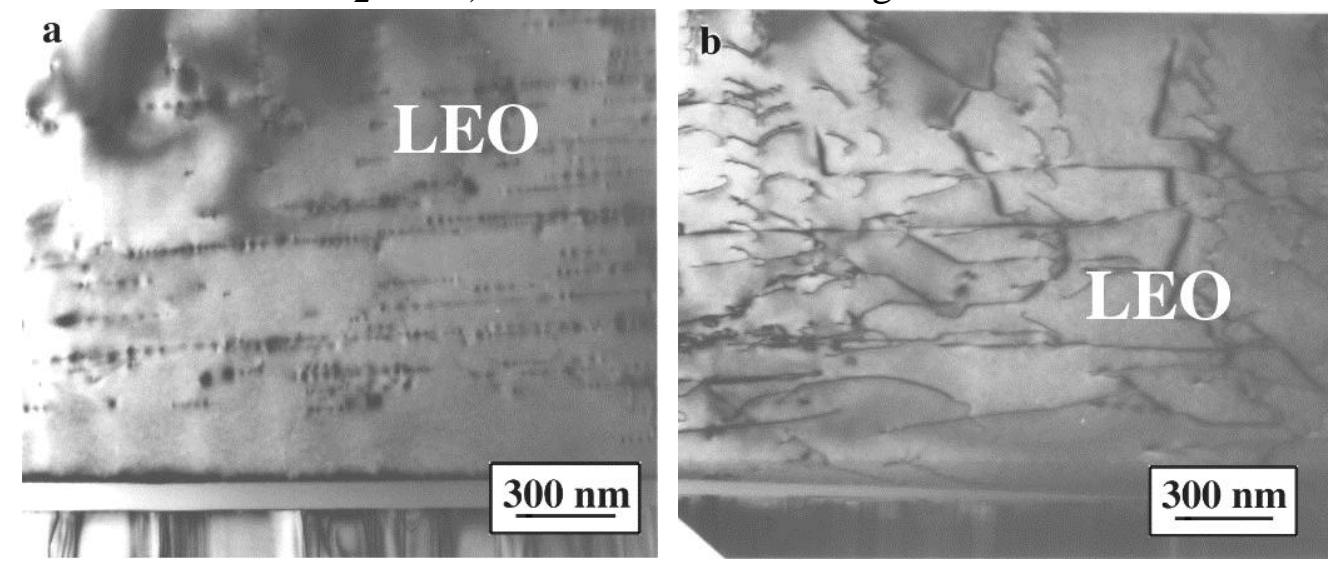

Fig. 5. Defects formed in the overgrown areas: (a) dislocation loops, (b) helical dislocations.

Misorientation between the two meeting growth fronts was also observed resulting in grain boundaries with much larger tilt and twist component than those normally observed in GaN grown on sapphire. Misorientation reveled by diffraction patterns taken on the two sides of the meeting fronts were different from strip to strip suggesting that this misorientation is determined by the particular subgrains from which the overgrowth starts. A very high dislocation density can 
be produced at the meeting points of two growing fronts. Mostly mixed and edge types of dislocations were formed in these areas. This high dislocation density is primarily a result of the misorientation between the two meeting growth fronts.

Beside planar defects on the c planes, helical dislocations were also observed in some overgrown areas suggesting a supersaturation of point defects. Accumulation of point defects could induce climb of straight dislocations having a screw orientation to form helical dislocations (Fig. 5b). Since these samples were not annealed after growth, it is believed that excess point defects are formed during growth and that they subsequently condense on dislocations during cooling from the growth temperature.

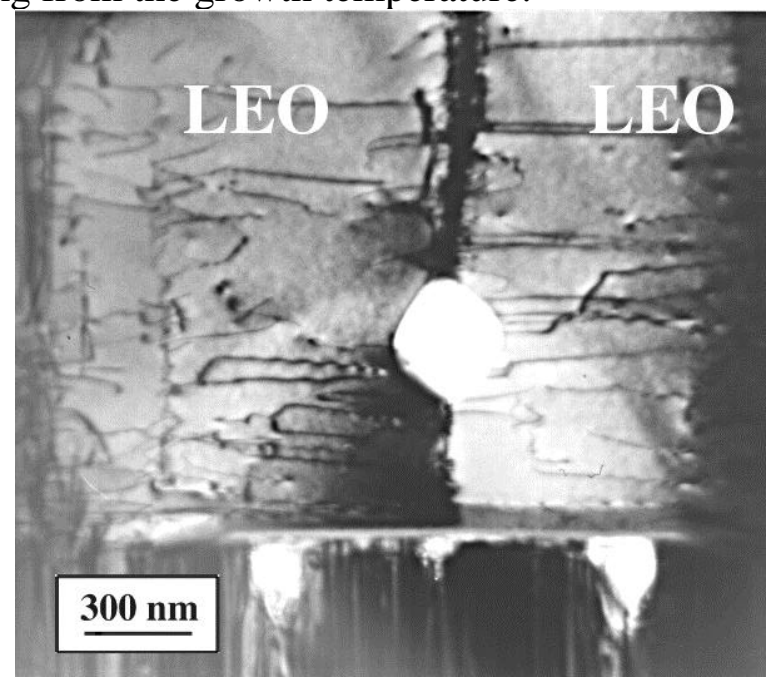

Fig. 6. Cross-section micrograph showing a void and dislocations at the meeting front of two overgrown strips

These results show that LEO samples contain three different areas with different types of defects and different defect densities. The homoepitaxial parts contain threading dislocations and other defects similar to traditionally grown samples. The laterally overgrown areas have planar defects (faulted dislocation loops), some bent threading dislocations and occasionally helical dislocations. Areas where two growth fronts meet, have voids and a high dislocation density at the boundary. It is logical to assume that by introducing a second $\mathrm{SiO}_{2}$ mask over homoepitaxial areas and carrying out a second overgrowth it should be possible to practically eliminate threading dislocations in the sample. However, in order to do this an increased number of masks would be required, e.g. masks need to be placed over the homoepitaxial parts of the layers and also over the meeting fronts of the first overgrown areas.

\section{CONCLUSIONS}

These observations show that by lateral overgrowth one can decrease the density of threading dislocations intersecting the growth surface. These are the most deleterious defects for device structures, since they continue to propagate into the next layer grown on top of the $\mathrm{GaN}$ layer. Planar defects are still formed in the overgrown areas and their density can reach the same value as the density of threading dislocations in GaN grown directly on sapphire. However, planar defects formed on c-planes do not propagate into any layer grown on top and so might be much less damaging for device structures. Also the density of these defects may be related to the 
impurity level in the sample. Different types of masks (without oxygen) might lead to a lower density of planar defects. The faceting of overgrown stripes was influenced by the crystallographic orientation and probably by the presence of impurities (since growth along [11 $\overline{2} 0]$ direction immediately leads to facet formation on energetically favorable slow growth (1 101$)$ planes inclined $62 ;$ to the c-plane).

Two types of defects were observed in the overgrown areas: dislocations (which change their line direction from vertical toward horizontal (parallel to the c-plane) and planar defectsmostly faulted dislocation loops that lie in the c plane. Occasionally helical dislocations were formed by interaction between screw dislocation segments and excess point defects.

At the boundaries where two growth fronts meet a much higher tilt and twist component was observed than that for subgrain boundaries in traditionally grown GaN. This misorientation was shown by diffraction patterns taken on the two sides of such boundaries. In addition, voids are also formed at these "meeting boundaries" which are most probably related to the presence of impurities, e.g. oxygen from the $\mathrm{SiO}_{2}$ masks.

Lateral overgrowth does appear to be a promising technique to achieve lower defect density, especially if impurity levels can be further reduced.

\section{ACKNOWLEDGMENT}

TEM work was supported by the Director, Office of Basic Science, Materials Science Division, U.S. Department of Energy, under the Contract No. DE-AC03-76SF00098. The use of the facility at the National Center for Electron Microscopy at Lawrence Berkeley National Laboratory is greatly appreciated. Crystal growth was supported by the National Science Foundation under Grant No. DMR-93-12947, the NSF Science and Technology Center Program under Grant No. CHE-89-20120 and partially by ONR under contract N00014-95-1-1302, monitored by J. C. Zolper.

\section{REFERENCES:}

1. T.S. Zheleva, O.H. Nam, M.D. Bremser, and R.F. Davis, Appl. Phys. Lett. 71, 2472 (1997).

2. T.S. Zheleva, O.H. Nam, J.D. Griffin, M.D. Bremser, and R.F. Davis, Mat. Res. Soc. Symp. 484, 393 (1998).

3. D. Kaplonek, S. Keller, R. Ventury, R.D. Underwood, P. Kozodoy, S.P. DenBaars, and U.K. Mishra, Appl. Phys. Lett. 71, 1204 (1997).

4. O.H. Nam, M.D. Bremser,T.S. Zheleva,and R.F. Davis, Appl. Phys. Lett. 71, 2638 (1997).

5. H. Marchand, J.P. Ibbetson, P.T. Fini, P. Kozodoy, S. Keller, J.S. Speck, S.P. DenBaars, and U.K. Mishra, MRS Internet J. Nitride Semicond. Res. 3, 3 (1998).

6. J. Park, P.A. Grudowski, C.J. Eiting, and R.D. Dupuis, Appl. Phys. Lett. 73, 333 (1998).

7. R.D. Dupuis, J. Park, P.A. Grudowski, C.J. Eiting, and Z. Liliental-Weber, J. Cryst. Growth in print.

8. Z. Liliental-Weber, Y. Chen, S. Ruvimov, and J. Washburn, "Formation Mechanism of Nanotubes in GaN” Phys. Rev. Lett. 79, 2835 (1997).

9. Z. Liliental-Weber, S. Ruvimov, W. Swider, Y. Kim, J. Washburn, S. Nakamura, R.S. Kern, Y. Chen, and J.W. Yang, MRS Proc. vol. 482, 375 (1998).

10. Z. Liliental-Weber, C. Kisielowski, S. Ruvimov, Y. Chen, J. Washburn, I. Grzegory, M. Bockowski, J. Jun, and S. Porowski, J. Electr. Mat. vol. 25 \#9, 1545-50. 